\title{
Geographies of production: Growth Regimes in Spatial Perspective 2 - Knowledge Creation and Growth in Clusters
}

\author{
Harald Bathelt
}

\begin{abstract}
Version Post-print/accepted manuscript
Citation Bathelt, H. (2005). Geographies of production: Growth regimes in (published version) spatial perspective (II) - Knowledge creation and growth in clusters. Progress in Human Geography, 29(2), 204-216.
\end{abstract}

Copyright / License

Publisher's Statement

The version of record [Bathelt, H. (2005). Geographies of production: Growth regimes in spatial perspective (II) - Knowledge creation and growth in clusters. Progress in Human Geography, 29(2), 204-216.] is available online at:

http://phg.sagepub.com/content/29/2/204 [doi: 10.1191/0309132505ph539pr]

How to cite TSpace items

Always cite the published version, so the author(s) will receive recognition through services that track citation counts, e.g. Scopus. If you need to cite the page number of the TSpace version (original manuscript or accepted manuscript) because you cannot access the published version, then cite the TSpace version in addition to the published version using the permanent URI (handle) found on the record page. 


\section{Geographies of production:}

\section{growth regimes in spatial perspective 2 - \\ knowledge creation and growth in clusters}

\section{Harald Bathelt}

Faculty of Geography, Philipps-University of Marburg,

Deutschhausstraße 10, D-35032 Marburg,

Germany

Progress Report on "Geographies of Production"

Forthcoming in

Progress in Human Geography 2005 (Vol. 29) 


\section{Setting the scene: the cluster debate}

Having questioned some of the assumptions in the literature on innovation systems in territorial contexts in my first report (Bathelt, 2003), this report discusses another class of concepts aimed at explaining localised industry configurations, i.e. cluster approaches. In line with my arguments presented, I argue that clusters can rarely be viewed as regional systems. At this geographical scale, a self-referential system is unlikely to develop because regions are strongly dependent on national institutions and other external influences and lack important political decision-making competencies.

Despite this, clusters have become one of the hotbeds of research in economics, sociology, political science and economic geography since the 1990s. It has become fashionable to apply cluster concepts to different industries and varying contexts in developed, less-developed or transforming economies (e.g. OECD, 1999). Much of this literature displays little critical reflection or applies clusters as a general policy model in an almost ideological way. As a result, scepticism has grown with regard to the universal applicability and adequate use of cluster concepts. Martin and Sunley (2003) present a detailed critique which identifies numerous problems related to fuzziness in the identification of clusters, lack of clarity and inconsistencies in the conceptualisation, insufficient empirical proof regarding the advantages of clusters (see, however, Porter, 2003) and the use of clusters as a 'one-model-fits-all' policy brand (see, also, Taylor, 2005).

The cluster approach has, however, been overly criticised for the inclusion of elements which are not specific to this concept (e.g. Benneworth and Henry, 2004; Malmberg and Power, 2003). One particular problem is that Martin and Sunley (2003) identify shortcomings in different versions of the cluster approach, all of which they basically attribute to the general conceptualisation of Michael Porter, the single most influential proponent of this literature (Porter, 1990; 1998; 2000). Benneworth and Henry (2004) argue that the original cluster 
concept has been developed further in various disciplines, influenced by their specific perspective, thus resulting in different versions. They view this as a strength rather than a weakness.

This report reviews some recent advances in the literature and argues for a multidimensional conceptualisation of clusters (Bathelt, 2004). This can help us understand why some clusters continue grow and reproduce themselves while others stagnate and disappear over time. This is done by focussing on the knowledge creation effects of clusters instead of their material flows (Malmberg and Maskell, 2002; Pinch et al., 2003).

\section{Point of departure: vertical and horizontal linkages in clusters}

In this report, the term 'cluster' is used to refer to a localised industry configuration, such as a local or regional concentration of industrial firms, and their support infrastructure which are closely interrelated through traded and untraded interdependencies (Maskell, 2001; Bathelt and Taylor, 2002). This deviates from Porter's (1990; 2003) conceptualisation of clusters as national bundles of industries which gain international competitiveness and are sometimes characterised by regional concentrations of firms (see, also, Preissl and Solimene, 2003; Malmberg and Power, 2003).

Porter $(1990,1998)$ distinguishes between the vertical and horizontal dimensions of clusters, a distinction which implies different competitive advantages for firms in the cluster (Maskell, 2001; Malmberg and Maskell, 2002; Enright, 2003). The vertical dimension encompasses firms with complementary products and competencies which can benefit from intensive transactions within the cluster and form networks of traded interdependencies. The horizontal dimension refers to those firms producing similar products (Maskell and Lorenzen, 2004). Competing firms with similar competencies have little reason to co-operate with one another or engage in close interaction. Co-location provides opportunities for firms to closely watch their competitors and compare their own economic performance with that of others. 
There are, however, many agglomerations and localised industry configurations which are characterised by economic stagnation or decline, despite the fact that they have developed along both dimensions. Clearly, the mere existence of vertical and horizontal cluster dimensions is not enough to generate knowledge and growth. I argue that a multidimensional perspective is needed to explain why clusters grow and how they reproduce themselves, emphasising issues of institutions, culture, power and external relations (Bathelt, 2004).

In the following sections, I focus on selected issues related to a multidimensional understanding of clusters. Section III explores ways in which coherent action can be established and maintained in a cluster, emphasising processes of institution building, the role of 'local buzz' and the impacts of communities of practice. In section IV, issues concerning the spatiality and global reach of clusters are discussed. Using a territorial conceptualisation of clusters, it will be shown that clusters need strong linkages to external markets and technologies developed outside the cluster to avoid processes of lock-in and maintain ongoing economic growth. Section V highlights cultural issues in globalisation processes. Effects of power and culture are discussed which are related to the extension of clusters towards other countries. Finally, section VI summarises the findings of the paper and discusses consequences for regional policy.

\section{Coherence and lack of coherence in clusters}

In order to exist as such over a longer time period, a cluster has to develop and maintain a structure which enables diversity within its area of competence, as well as a minimum of coherence in its focus. This includes the development of a common identity surrounding a particular value chain and the need for firms to share similar views and make similar decisions with respect to technological choices. In other words, a joint institutional basis and its reproduction are necessary for economic interaction. Industrial clustering has clearly more advantages than those due to cost savings and traded interdependencies. Concepts, such as 
localised capabilities (Maskell and Malmberg, 1999) and untraded interdependencies (Storper, 1997), emphasise that socio-institutional settings, interfirm communication and interactive learning play a decisive role in explaining regional innovation and growth (Cooke and Morgan, 1999; Lawson, 1999; Gordon and McCann, 2000). The process of institution building is shaped and stimulated by existing communication practices, the quality of local buzz and the formation of communities.

\section{Reproductivity and buzz}

Norms, accepted rules, habits, conventions and other institutional arrangements are of central importance to enable interfirm communication and collaboration within a cluster (Amin and Thrift, 1995; Wolfe and Gertler, 2004). A joint institutional framework allows specialised users and producers to discuss and solve particular problems (Hodgson, 1988; North, 1990). Such a framework does not, however, exist automatically. It is created through social practices in day-to-day interactions. Joint problem-solving and experimentation lead to preliminary fixes which must be robust to survive the next series of interactions. These fixes are constantly being updated or adjusted to meet new goals in the innovation process (Storper, 1997; McKelvey, 1997). The creation of institutions within a cluster helps to stabilise producer-user relations and stimulates trust (Granovetter, 1985; Lorenz, 1999; Lawson and Lorenz, 1999).

Co-location and face-to-face contacts within a cluster generate further advantages related to the circulation of information and inspiration (Bathelt et al., 2004). They stimulate a particular local buzz which is related to continuous and updated flows of information and intended and unanticipated learning processes which are based on the same institutional setup (Storper and Venables, 2004). Actors do not have to search their environment or make particular investments to get access to this information. They are automatically exposed to 
news reports, gossip, rumours and recommendations about technologies, markets and strategies by just being in the cluster (Gertler, 1995, 2003; Grabher, 2002a).

The existence of a widely accepted set of institutions allows firms within a cluster to develop reasonable expectations regarding the actions of others and to participate in the local buzz. This generates connectivity and encourages continuity in communication. New steps in innovation processes follow the resolution of previous problems. Co-location thus serves as a powerful means to participate in the process of creating institutions and stimulates knowledge transfer.

\section{Community building}

The process of institution building can be mediated through or strongly supported by communities of practice (Brown and Duguid, 1991; Wenger, 1998). These communities are virtually self-organised and are bound together through day-to-day interaction and regular meetings. Community members tell stories about their work to bridge the gap between theoretical and practical knowledge (Brown and Duguid, 2000). This helps in the exchange of existing knowledge, the generation of new knowledge and development of competencies. Communities are important in processes of problem-solving, strategy and business development and the diffusion of best practices. Specialists voluntarily join these communities, stimulating mutual commitment and an identification with the group's competence basis (Wenger and Snyder, 2000). ${ }^{1}$

Communities of practice can develop within a firm but may also span a single organisation and include other firms in a value chain, particularly within a cluster (Gertler, 2001; Grabher, 2002b). According to Benner (2003), such communities have played an important role for individuals in Silicon Valley in acquiring and maintaining specialised competencies. Shared experiences in solving the same sort of problems based on the same 
technological paradigm support the development of mutual engagement, joint enterprise, shared repertoire and negotiation of meaning (Wenger, 1998; Coe and Bunnell, 2003).

The coherent development of a cluster can be an important catalyst for the formation of such communities. Existing communities or parts thereof, in turn, serve to stabilise social relations in the cluster. They develop into local frames for understanding the meaning and significance of local buzz and stimulate the generation of even more local buzz and its rapid diffusion.

\section{Spatial boundaries and openness of clusters}

Unresolved issues with respect to the cluster debate are particularly related to questions of definition and spatial extent. The lack of a precise definition of the sectoral and spatial characteristics of a cluster has been a major criticism of Porter's (1990; 1998) work (Martin and Sunley, 2003). According to Porter (2000), clusters can exist at a local, regional or even interregional and cross-national level, although he still seems to prefer his original idea that clusters are bundles of interrelated industries within a nation-state (Porter, 2003). The reason why it is seemingly easy to transfer this concept to different spatial scales is that it does not encompass an explanation for the internal mechanisms which are responsible for the spatial relations and boundaries of the cluster.

A key problem of Porter's $(1990 ; 2000)$ cluster concept is that it lacks a sound institutional framework. In applying an institutional perspective, the expectation that a precise, all-encompassing definition for clusters can be found appears unrealistic. Since institutional contexts vary between technologies and between nation-states, clusters can be characterised by a different sectoral mix, complexity and spatial reach. 


\section{Spatiality of clusters}

There is no generally accepted spatial definition for clusters. Depending on the method and basic spatial unit used, the number of potential clusters identified in a country can vary drastically. Top-down approaches, such as those by Ellison and Glaeser (1997), Porter (2003) and Sternberg and Litzenberger (2003), are unlikely to identify a complete set of clusters of different types. A top-down macroeconomic methodology does not consider that clusters may be at different stages in their development path and that their characteristics could change over time (Belussi, 2004). Such approaches also lack a convincing explanation as to when a spatially concentrated industry could be defined as a cluster. Simple measures of co-location or location quotients do not suffice to identify clusters because they do not provide insights into the structure of social relations and patterns of economic interaction. Bottom-up approaches which try to define clusters through a generalisation of case study results are, of course, also problematic.

Another group of cluster definitions proceed in a different way. They suggest the application of a functional, value-chain-based understanding of clusters which does not incorporate a territorial dimension aside from the nation-state (Feser and Bergman, 2000; Preissl and Solimene, 2003). This is also the approach favoured by Porter (2003). Some argue that the advantages of regional clustering and proximity in transactions and knowledge creation diminish due to the effects of modern communication and transportation (Feser and Bergman, 2000). From this, Preissl and Solimene (2003) imply that a regional cluster concept is obsolete. Instead, they identify innovation clusters according to innovation linkages in the value chain, regardless of their spatiality. The problem of such approaches is that they use 'spaceless' conceptualisations of clusters in the first place and then attempt to identify their spatial consequences, instead of integrating a spatial perspective from the very beginning. This is also not very helpful from a regional development and policy view. Studies by the 
OECD (1999) are even more confusing because their understanding of clusters allows for the use of each of the above-mentioned approaches.

In contrast, this report adopts a regional perspective on clusters, where the term refers to a local or regional concentration of industrial firms and their support infrastructure closely interrelated through traded and untraded interdependencies (Maskell, 2001; Bathelt, 2002). Using this definition, regional concentrations of firms of a given value chain, or parts thereof, can be identified. This does not, of course, imply that every agglomeration of firms can be categorised as having the same growth potential and regional impact. Clusters need to be analysed along several dimensions; i.e. their horizontal, vertical, institutional, external and power dimensions. In this way, different types and configurations of clusters can be identified. Of course, not every cluster covers a major part of a particular value chain or is characterised by a sound, self-sustained institutional basis. In addition, not all regional economies have their own clusters (Storper, 1997; Hellmer et al., 1999). Using a multidimensional approach, the strengths and weaknesses of clusters, their capability to reproduce themselves and initiate self-sufficient growth can be identified. In such an approach, the cluster concept becomes an analytical instrument rather than an ideology. It is a tool for the analysis of regional growth paths and can support the development of regional policy programs.

\section{Beyond the cluster}

In recent years, it has become clear that clusters cannot be narrowly conceptualised by focussing on their internal linkages but must also recognise their external dimension (Malmberg et al., 1996; Bathelt, 2002; Wolfe and Gertler, 2004). A cluster cannot unfold its full growth potential if its firms mainly rely on internal markets and knowledge. If local linkages between suppliers, producers and customers become too rigid and too exclusive, concentrating on only a few local actors, this could cause lock-in and pose limitations on future growth (Granovetter, 1973; Scott, 1998; Maillat, 1998; Oinas, 1999). This problem, 
which has also been described as over-embeddedness (Uzzi, 1997; Bathelt and Taylor, 2002; Sofer and Schnell, 2002), exemplifies that the degree of openness in a cluster must be large enough to allow for maximum external innovation and growth impulses.

If we were to define a cluster in a functional way based on its value chain, this problem would be overlooked. As Humphrey and Schmitz (2002) have pointed out, there are basically two different concepts which can be used as a basis to study the development of production networks, i.e. clusters and global commodity chains (e.g. Cooke, 2003). Of these approaches, the cluster concept tends to explain economic success by referring to the local networks of social relations between firms while neglecting extra-local linkages. In contrast, the concept of global commodity chains (Gereffi, 1994; 1999) emphasises the advantages of functional production organisation and corresponding governance structures but underestimates the territorial dimension and localised nature of production arrangements. In order to bring both perspectives closer together, Dicken et al. (2001) and Henderson et al. (2002) have developed the concept of global production networks, a more spatially-oriented approach which builds on actor-networks and social and territorial embeddedness.

A preferred alternative approach which complements the work on global production networks is the application of a cluster concept which systematically integrates value-chainbased linkages and a cluster's external dimension. Through this, emphasis is placed on the particular region under investigation and its external relations. Studies have shown that partnerships with firms located outside the cluster are decisive triggers for innovation (e.g. Hendry et al., 2000; Vatne, 2001; Tracey and Clark, 2003; Clark and Tracey, 2004). With the establishment of trans-local pipelines between different clusters, regions or nation-states (Owen-Smith and Powell, 2004; Bathelt et al., 2004), firms can tap into external knowledge pools and markets. As opposed to the local buzz, access to trans-local pipelines does not, however, happen spontaneously. It requires conscious efforts, substantial investments and is 
associated with higher uncertainty. Partners in pipelines need to be carefully selected and trust must develop (Lorenz, 1999). Firms at both ends need to familiarise themselves with one another, learn how to make interactive adjustments and develop an absorptive capacity (Cohen and Levinthal, 1990; Malecki, 2000). They have to be able to assimilate external information and apply it internally. The argument here is that the success of a cluster is fundamentally based on the external linkages of its firms.

\section{Crossing institutional boundaries}

The role of institutions becomes, of course, more complicated when firms in a cluster exchange goods and knowledge through global pipelines. Different rules of the game exist and cultural differences can provide a barrier to communication and knowledge transfer. Actors are socialised in a particular societal context and adjust their habits to the corresponding institutional mix (Hall and Soskice, 2001; Hodgson, 2003). When firms establish production linkages in a new country they are faced with a heterogeneous cultural and institutional environment. Firms have to bridge these differences, establish efficient communication between agents with various cultural backgrounds and adjust their organisational practices to those in the host country.

\section{Inter-cultural knowledge flows}

A number of studies have argued that economic interaction and knowledge creation are no longer bound to particular regional settings but can be replaced by relational proximity between actors located in different parts of the world (Amin and Cohendet, 1999; Oinas, 1999; Lee, 2001). According to Thrift (2000) and Amin and Cohendet (2004), the global movements and communication of business people have generated new opportunities to establish business relations across space. This is accomplished through: 
(i) executive travellers who meet repeatedly in neutral places around the world for intensive face-to-face communication;

(ii) internet 'thinking studios' which enable virtual communication around the globe;

(iii) transnational epistemic communities, consisting of people who become boundary spanners between different cultures (e.g. Coe and Bunnell, 2003; Rallet and Torre, 2004);

(iv) international trade fairs and other professional gatherings in which leading firms of an industry exchange information about advanced products and innovations (Maskell et al., 2004).

However, the difficulties in establishing and maintaining such interactions across national boundaries are easily underestimated. If cluster firms aim to establish trans-local linkages with firms in other parts of the world, an understanding of different institutional regimes is needed. This requires complex capabilities which are not that easy to achieve, as firms tap into particular cultures which can vary between places, regions and nation-states (Saxenian, 1994; Schoenberger, 1999; Gertler, 2004).

Cultural contexts can strongly influence economic action (Crang, 1997; Boeckler and Lindner, 2000; Casson and Godley, 2000; Porter, 2002; Amin and Thrift, 2003) because they involve implicit and explicit norms, rules, convictions, moral codes and philosophies of life which are accepted by or imposed upon its members. These have developed through a history of social relations and are produced and reproduced in everyday's practices (Lash and Urry, 1994; Sayer, 1997; Power, 2002). A cultural context creates an institutional framework for human interaction which differs from that in other cultures. At the same time, rules and norms are constantly being reshaped and new ones created. Therefore, culture cannot be reduced to a fixed number of characteristics. It is a fluid phenomenon, constantly in a state of flux (Cavallardo, 2001; Berndt, 2003). Gertler (2001) points out that systematic influences of institutions prevent the diffusion of universal operational standards at a global scale. The 
nation-state does not only support the development of symbols, meanings and language associated with a culture; it also stimulates particular ways of economic action and interaction through formal and informal institutions.

If the strategies, goals and structures of firms are deeply influenced by the institutional settings of the national political economy in which they are embedded, new institutions have to be established or existing ones adjusted to enable coherent strategic interaction in an intercultural setting. Particularly important are institutions which support the exchange of information, monitor the actions of others and enable actors to engage in joint discussions and co-operation. This is, however, easier said than done. Institutional complementarities are more likely to develop in a homogeneous cultural setting, such as a nation-state (Lundvall and Maskell, 2000; Hall and Soskice, 2001). In an inter-cultural context, different governance structures might be implemented as a consequence involving, for instance, loose decentralised interactions within the cluster and more hierarchical governance in external relations.

\section{Power relations and boundary spanners}

There are at least two aspects of power which need to be explored further in the context of innovation and growth: coherence within a cluster and the co-ordination of the external relations of cluster actors.

A cluster does not automatically encompass a coherent group of firms which co-operate harmoniously with one another to achieve a common set of goals. A cluster's horizontal and vertical dimensions are shaped by existing power relations and asymmetries which impact upon the agents' ability to react to changes in their regulatory environment and external markets (Taylor, 2000; Bathelt and Taylor, 2002). The question is, therefore, which mechanisms create consistent behaviour within a cluster? It could be argued that a cluster can only be considered as such if the actors and firms recognise the cluster as an entity which is 
sufficiently different from its environment and act accordingly. In this case, clusters have an emergent effect and become visible to others (Yeung, 1994; Dicken et al., 2001).

Within a cluster, control over resources is not enough for an agent to become powerful (Latour, 1986; Thrift, 1996). Actors which are viewed to have power are those able to build networks and develop them further by enrolling other actors (Allen, 1997; Smith, 2003; Jöns, 2003). Existing social relations are reinforced through communication between the actors and joint decisions made about technologies. The power of a cluster can thus be understood as the potential to enrol cluster firms in joint enterprises.

Of course, it is difficult to establish coherence within a cluster through social relations alone. Material and non-material resources, such as non-human artefacts (e.g. particular technologies, symbols), tools (e.g. manuals, reports) and accepted rules, enable human actors to engage in social relations and maintain them (Latour, 1986; Murdoch, 1995). In a cluster, process and communication technologies serve to stabilise interactions between firms, as they have similar day-to-day experiences and develop the same understanding. In an inter-cultural context, shared technologies and existing norms and rules are particularly important to support economic interaction and achieve common goals. Material and non-material resources clearly help shape the course of action. Without them, messages and requests could be easily misinterpreted and technologies used inappropriately.

Since the coherence of a cluster and its ability to work are dependent on day-to-day interactions, distance and visibility are of great importance (Crang, 1997). They enable ongoing exchange with others through a multitude of micro-practices and help exercise control over their activities. An important question is how can social relations be maintained over distance if the actors do not have regular face-to-face contact? It is not an easy task to exercise power over distance (Murdoch, 1995; Allen, 1997). It requires that effective 
technologies and routines are introduced, enabling actors to check the outcomes of their orders which occur in different places.

Network builders who are able to enrol others into networks are particularly important in the process of network activation and formation. In an inter-cultural context, boundary spanners are also important as they have the potential to communicate between those involved and help provide an understanding of heterogeneous habits and attitudes. Coe and Bunnell (2003) emphasise the significance of transnational communities in translating news, claims and problems between the different nationalities and parties in an inter-cultural production setting (e.g. Hsu and Saxenian, 2000; Smith, 2003; Depner and Bathelt, 2005). These are people who have lived and worked in different cultural contexts and are able to understand the different expectations and patterns of behaviour and clarify them between actors. Their ability to stimulate communication might, in part, determine the long-term success of clusters in an international market environment.

\section{Conclusions: clusters and policy issues}

In this report, I have discussed some open questions and aspects of debate with respect to the cluster approach. Aspects regarding the existence, growth and reproduction of clusters have been analysed in spatial perspective. It is argued that a regional approach towards clusters, viewing clusters as regional concentrations of firms in a value chain or parts of it, provides a well-suited device for the analysis of regional growth paths and the support of policy programs. To identify different organisational configurations, (potential) clusters should be analysed along multiple dimensions; i.e. their vertical, horizontal, institutional, external and power dimensions. In this perspective, clusters cannot exist without systematic external linkages to suppliers, markets and technologies, raising issues of inter-cultural coordination, power and control. 
In policy terms, we should be aware that clusters cannot be used as a 'one-model-fits-all' strategy (Martin and Sunley, 2003). One of the key issues of designing a cluster policy is to develop a regional industry structure which is sufficiently specialised to benefit from traded and untraded interdependencies, yet diversified enough to avoid the danger lock-in. It is unlikely that this trade-off can be resolved as a simple optimisation problem. The countervailing forces, power asymmetries and divergent interests of actors are always at work in a cluster. There is no single equilibrium that resolves the inherent tensions, only temporary stabilisations of unequal power relations (Bathelt and Taylor, 2002).

The arguments presented in this report do not imply that regional policies should always be designed as cluster policies or that policy initiatives can easily create new clusters. Studies have shown that there are plenty of 'normal regions' or 'non-core regions' which do not exhibit economic specialisation (Storper, 1997; Hellmer et al., 1999). They do not have the potential to stimulate self-sustaining growth processes or develop into clusters. Further, dynamic urban areas can be found which do not have much in common with a cluster (Newlands, 2003; Bramwell et al., 2004). At the same time, several clusters may overlap in other large metropolitan areas (Crevoisier, 2001; Porter, 2003; Bathelt and Boggs, 2005), possibly creating synergies and strengthening the regional economy.

It is questionable whether a standard cluster policy would be the best regional policy approach in all these settings. In broad, diversified metropolitan areas, for instance, the regional growth path might benefit from a large variety of urbanisation instead of localisation economies. The Waterloo region, one of the most dynamic regions of high-technology growth in Canada, falls into this category as it does not host a true cluster of interrelated firms tied to a particular value chain. Co-location is seemingly not the driving force behind the regional growth process (Parker, 2001; Bramwell et al., 2004). Here and in other regions, the processes enabling dynamic growth might indeed be quite different from those in clusters 
(Crevoisier, 2001; Simmie, 2003), making these regions particularly robust against economic shocks. Further, as Wolfe and Gertler (2004) have pointed out, the success of a regional cluster policy is also dependent on the wider institutional context at the national and supranational and not only the regional level. Some conceptualisations might even conclude that a particular regional policy is not required to stimulate cluster development (Newlands, 2003).

Based on a study of a number of industrial clusters in different parts of the world, Bresnahan et al. (2001) found that the reasons behind the establishment of new clusters are much different from those which support the growth of existing ones. They did not find much evidence that state policies had a notable influence on the establishment of the clusters in the first place. According to their work, the degree of openness in regional economic relations and access to large external markets are critical factors determining the success of emergent clusters. Further, it would be unlikely that clusters could be jumpstarted through regional policy initiatives alone. On the contrary, it appears misleading to assume that policy initiatives could not support cluster growth at all. There are examples which show that policies can have a significant impact on cluster development, even in early stages (e.g. Feldman, 2001; Lundequist and Power, 2002; Depner and Bathelt, 2005). There is, however, little systematic analysis of the performance of policy programs (Enright, 2003).

Overall, it is necessary to develop contextualised cluster policies, leaving room for alternative policies if the local growth path does not depend on clusters or if clusters are not at the core of regional competitiveness. Cluster policies, if chosen, have to be multidimensional policies, sensitive to the specificities of the local economy and the embeddedness of local industry structures. 


\section{Acknowledgements}

I would like to thank particularly Ulrich Dewald, Peter Dicken, Armin Gräf and Clare

Wiseman for their helpful suggestions on a first draft of this report.

\section{Notes}

${ }^{1}$ A concept related to communities of practice is that of epistemic communities (Knorr Cetina, 1999). As opposed to communities of practice, epistemic communities are organised by and structured around a procedural authority to reach a specified goal (Amin and Cohendet, 2004). Agents become members of this focussed community depending on how well they can contribute to that goal. Autonomy and self-organisation are weaker and hierarchies stronger than in communities of practice. Characteristic of such communities is the desire of agents for knowledge creation, the focus on group creativity and the creation of institutional fixes.

\section{References}

Allen, J. 1997: Economies of power and space. In Lee, R. and Wills, J., editors, Geographies of economies, London: Arnold, 59-70.

Amin, A. and Cohendet 1999: Learning and adaptation in decentralized business networks. Environment and Planning D: Society and Space 17, 87-104.

Amin, A. and Cohendet, P. 2004: Architectures of knowledge: firms, capabilities, and communities. Oxford and New York: Oxford University Press.

Amin, A. and Thrift, N. 1995: Living in the global. In Amin, A. and Thrift, N., editors, Globalization, institutions, and regional development in Europe, Oxford and New York: Oxford University Press, 1-22.

Amin, A. and Thrift, N., editors 2003: The Blackwell cultural economy reader. Oxford: Blackwell.

Bathelt, H. 2002: The re-emergence of a media industry cluster in Leipzig. European Planning Studies 10, 583-611.

Bathelt, H. 2003: Geographies of production: growth regimes in spatial perspective 1 innovation, institutions and social systems. Progress in Human Geography 27, 763-778.

Bathelt, H. 2004: Toward a multidimensional conception of clusters: the case of the Leipzig 
media industry, Germany. In Power, D. and Scott, A. J., editors, Cultural industries and the production of culture, Abingdon and New York: Routledge, 147-168.

Bathelt, H. and Boggs, J. S. 2005: Continuities, ruptures and re-bundling of regional development paths: Leipzig's metamorphosis. In Fuchs, G. and Shapira, P., editors, Rethinking regional innovation and change: path dependency or regional breakthrough?, New York: Springer, 147-170.

Bathelt, H. and Taylor, M. 2002: Clusters, power and place: inequality and local growth in time-space. Geografiska Annaler 84B: 93-109.

Bathelt, H., Malmberg, A. and Maskell, P. 2004: Clusters and knowledge: local buzz, global pipelines and the process of knowledge creation. Progress in Human Geography 28, 31 56.

Belussi, F. 2004: In search of a useful theory of spatial clustering. Paper presented at the 4th Congress on Proximity Economics 'Proximity, Networks and Co-ordination' in Marseille, 17-18 June.

Benner, C. 2003: Learning communities in a learning region: the soft infrastructure of crossfirm learning networks in Silicon Valley. Environment and Planning A 35, 1809-1830.

Benneworth, P. and Henry, N. 2004: Where is the value added in the cluster approach? Hermeneutic theorising, economic geography and clusters as a multiperspectival approach. Urban Studies 41, 1011-1023.

Berndt, C. 2003: El Paso del Norte ... Modernization utopias, othering and management practices in Mexico's maquiladora industry. Antipode 35, 264-285.

Boeckler, M. and Lindner, P. 2000: Jüngere Tendenzen im Umgang mit Kultur und Region in der Wirtschafts- und Sozialgeographie (Recent tendencies on the role of culture and region in economic and social geography). In Bahadir, S. A., editor, Kultur und Region im Zeichen der Globalisierung (Culture and region in the age of globalisation), Neustadt/Aisch: Degener, 105-128.

Bramwell, A., Nelles, J. and Wolfe, D. A. 2004: Knowledge, innovation and regional culture in Waterloo's ICT cluster. Paper presented at the Innovation Systems Research Network (ISRN) National Meeting in Vancouver, 12-15 May.

Bresnahan, T., Gambardella, A. and Saxenian, A. 2001: 'Old economy' inputs for 'new economy' outcomes: cluster formation in the new Silicon Valleys. Industrial and Corporate Change 10, 835-860.

Brown, J. S. and Duguid, P. 1991: Organizational learning and communities of practice: toward a unified view of working, learning, and innovation. Organization Science 2, 40- 
57.

Brown, J. S. and Duguid, P. 2000: Balancing act: how to capture knowledge without killing it. Harvard Business Review 78 (May-June), 73-80.

Casson, M. and Godley, A. 2000: Cultural factors in economic growth. Berlin: Springer.

Cavallardo, D. 2001: Critical and cultural theory: thematic variations. London and New Brunswick, NJ: Athlone.

Clark, G. L. and Tracey, P. 2004: Global competitiveness and innovation: an agent-centred perspective. Houndsmill and New York: Palgrave Macmillan.

Coe, N. M. and Bunnell, T. G. 2003: 'Spatializing' knowledge communities: towards a conceptualisation of transnational innovation networks. Global Networks 3: 437-456.

Cohen, W. M. and Levinthal, D. A. 1990: Absorptive capacity: a new perspective on learning and innovation. Administrative Science Quarterly 35, 128-152.

Cooke, P. 2003: Regional innovation and learning systems, clusters, and local and global value chains. In Bröcker, J., Dohse, D. and Soltwedel, R., editors, Innovation clusters and interregional competition, Berlin and Heidelberg: Springer, 28-51.

Cooke, P. and Morgan, K. 1998: The associational economy. Oxford: Oxford University Press.

Crang, P. 1997: Cultural turns and the (re)constitution of economic geography. In Lee, R. and Wills, J., editors, Geographies of economies, London and New York: Arnold, 3-15.

Crevoisier, O. 2001: Der Ansatz des kreativen Milieus: Bestandsaufnahme und

Forschungsperspektiven am Beispiel urbaner Milieus (The creative milieu: state of the art, research perspectives and the case of urban milieus). Zeitschrift für

Wirtschaftsgeographie 45, 246-256.

Depner, H. and Bathelt, H. 2005: Exporting the German model: the establishment of a new automobile industry cluster in Shanghai, P.R. China. Economic Geography 81, forthcoming.

Dicken, P., Kelly, P. F., Olds, K. and Yeung, H. W.-c. 2001: Chains and networks, territories and scales: towards a relational framework for analysing the global economy. Global Networks 1: 89-112.

Ellison, G. and Glaeser, E. L. 1997: Geographic concentration in the U.S. manufacturing industries: a dartboard approach. Journal of Political Economy 105, 889-926.

Enright, M. J. 2003: Regional clusters: what we know and what we should know. In Bröcker, J., Dohse, D. and Soltwedel, R., editors, Innovation clusters and interregional competition, Berlin and Heidelberg: Springer, 99-129. 
Feldman, M. 2001: The entrepreneurial event revisited: firm formation in a regional context. Industrial and Corporate Change 10, 861-891.

Feser, E. J. and Bergman, E. M. 2000: National industry cluster templates: a framework for applied regional cluster analysis. Regional Studies 34, 1-20.

Gereffi, G. 1994: The organization of buyer-driven global commodity chains: how US retailers shape overseas production networks. In Gereffi, G. and Korzeniewicz, M., editors, Commodity chains and global capitalism, Westport, CT: Praeger, 95-122.

Gereffi, G. 1999: International trade and industrial upgrading in the apparel commodity chain. Journal of International Economics 48, 37-70.

Gertler, M. S. 1995: 'Being there': proximity, organization, and culture in the development and adoption of advanced manufacturing technologies. Economic Geography 71, 1-26.

Gertler, M. S. 2001: Best practice? Geography, learning and the institutional limits to strong convergence. Journal of Economic Geography 1, 5-26.

Gertler, M. S. 2003: Tacit knowledge and the economic geography of context, or The undefinable tacitness of being (there). Journal of Economic Geography 3, 75-99.

Gertler, M. S. 2004: Manufacturing culture: the institutional geography of industrial practice. Oxford and New York: Oxford University Press.

Gordon, I. R. and McCann, P. 2000: Industrial clusters: complexes, agglomeration and/or social networks. Urban Studies 37, 513-532.

Grabher, G. 2002a: Cool projects, boring institutions: temporary collaboration in social context. Regional Studies 36, 205-214.

Grabher, G. 2002b: The project ecology of advertising: tasks, talents and teams. Regional Studies 36, 245-262.

Granovetter, M. 1973: The strength of weak ties. American Journal of Sociology 78, 13601380.

Granovetter, M. 1985: Economic action and economic structure: the problem of embeddedness. American Journal of Sociology 91, 481-510.

Hall, P. A. and Soskice, D. 2001: An introduction to varieties of capitalism. In Hall, P. A. and Soskice, D., editors, Varieties of capitalism: the institutional foundations of comparative advantage, Oxford and New York: Oxford University Press, 1-68.

Hellmer, F., Friese, C., Kollros, H. and Krumbein, W. 1999: Mythos Netzwerke: Regionale Innovationsprozesse zwischen Kontinuität und Wandel (The network myth: continuity and change in regional innovation). Berlin: Edition Sigma - Bohn.

Henderson, J., Dicken, P., Hess, M., Coe, N. and Yeung, H. W.-c. 2002: Global production 
networks and the analysis of economic development. Review of International Political Economy 9, 436-464.

Hendry, C., Brown, J. and DeFillippi, R. 2000: Regional clustering of high technology-based firms: opto-electronics in three countries. Regional Studies 34, 129-144.

Hodgson, G. M. 1988: Economics and institutions: a manifesto for a modern institutional economics. Cambridge: Polity Press.

Hodgson, G. M. 2003: The hidden persuaders: institutions and individuals in economic theory. Cambridge Journal of Economics 27: 159-175.

Hsu, J.-y. and Saxenian, A. 2000: The limits to guanxi capitalism: transnational collaboration between Taiwan and the US. Environment and Planning A 32, 1991-2005.

Humphrey, J. and Schmitz, H. 2002: How does insertion in global value chains affect upgrading in industrial clusters? Regional Studies 36, 1017-1027.

Jöns, H. 2003: Von Menschen und Dingen: Konstruktivistisch-kritische Anmerkungen zum (a)symmetrischen Akteurskonzept der Akteursnetzwerktheorie (Humans and non-humans: critical comments on the (a)symmetrical actor concept in actor-network theory). In Hasse, J. and Helbrecht, I., editors, Menschenbilder in der Humangeographie (Human Images in Human Geography), Oldenburg: Bibliotheks- und Informationssystem, 109-142.

Knorr Cetina, K. 1999: Epistemic cultures: how the sciences make sense. Chicago: Chicago University Press.

Lash, S. and Urry, J. 1994: Economies of signs and spaces. London: Sage.

Latour, B. 1986: The powers of association. In Law, J., editor, Power, action and belief: a new sociology of knowledge?, London: Routledge and Kegan Paul, 264-280.

Lawson, C. 1999: Towards a competence theory of the region. Cambridge Journal of Economics 23, 151-166.

Lawson, C. and Lorenz, E. 1999: Collective learning, tacit knowledge and regional innovative capacity. Regional Studies 33, 302-317.

Lee, J. H. 2001: Geographies of learning and proximity reconsidered: a relational/organizational perspective. Journal of the Korean Geographical Society 36: 539-560.

Lorenz, E. 1999: Trust, contract and economic cooperation. Cambridge Journal of Economics $23,301-315$.

Lundequist, P. and Power, D. 2002: Putting Porter into practice? Practices of regional cluster building: evidence from Sweden. European Planning Studies 10, 685-704.

Lundvall, B.-Å. and Maskell, P. 2000: Nation states and economic development: from 
national systems of production to national systems of knowledge creation and learning. In Clark, G. L., Feldman, M. P. and Gertler, M. S., editors, The Oxford handbook of economic geography, Oxford: Oxford University Press, 353-372.

Maillat, D. 1998: Vom 'Industrial District' zum innovativen Milieu: Ein Beitrag zur Analyse der lokalen Produktionssysteme (From industrial networks to innovative milieus: towards an analysis of territorial production systems). Geographische Zeitschrift 86, 1-15.

Malecki, E. J. 2000: Knowledge and regional competitiveness. Erdkunde 54, 334-351.

Malmberg, A. and Maskell, P. 2002: The elusive concept of localization economies: towards a knowledge-based theory of spatial clustering. Environment and Planning A 34, 429-449.

Malmberg, A. and Power, D. 2003: (How) do (firms in) clusters create knowledge? Paper presented at the Danish Research Unit on Industrial Dynamics Summer Conference 'Creating, Sharing and Transferring Knowledge. The Role of Geography, Institutions and Organizations' in Copenhagen, 12-14 June (URL:

http://www.druid.dk/conferences/summer2003/Papers/MALMBERG_POWER.pdf, date accessed: 19 January 2005).

Malmberg, A., Sölvell, Ö. and Zander, I. 1996: Spatial clustering, local accumulation of knowledge and firm competitiveness. Geografiska Annaler 78B, 85-97.

Martin, R. and Sunley, P. 2003: Deconstructing clusters: chaotic concept or policy panacea? Journal of Economic Geography 3, 5-35.

Maskell, P. 2001: Towards a knowledge-based theory of the geographical cluster. Industrial and Corporate Change 10, 921-943.

Maskell, P., Bathelt, H. and Malmberg, A. 2004: Temporary clusters and knowledge creation: the effects of international trade fairs, conventions and other professional gatherings. Spatial Aspects Concerning Economic Structures Working Paper (SPACES) 2004-04. Marburg: Faculty of Geography, Philipps-University of Marburg (URL: http://www.unimarburg.de/geographie/spaces, date accessed: 19 January 2005).

Maskell, P. and Lorenzen, M. 2004: The cluster as market organisation. Urban Studies 41, 991-1009.

Maskell, P. and Malmberg, A. 1999: The competitiveness of firms and regions: 'ubiquitification' and the importance of localized learning. European Urban and Regional Studies 6: 9-25.

McKelvey, M. 1997: Using evolutionary theory to define systems of innovation. In Edquist, C., editor, Systems of innovation: technologies, institutions and organizations, London: Pinter, 200-222. 
Murdoch, J. 1995: Actor-networks and the evolution of economic forms: combining description and explanation in theories of regulation, flexible specialization, and networks. Environment and Planning A 27, 731-757.

Newlands, D. 2003: Competition and cooperation in industrial clusters: the implications for public policy. European Planning Studies 11, 521-532.

North, D. C. 1990: Institutions, institutional change and economic performance. Cambridge: Cambridge University Press.

Oinas, P. 1999: Activity-specificity in organizational learning: implications for analysing the role of proximity. GeoJournal 49, 363-372.

Organization for Economic Cooperation and Development (OECD) 1999: Boosting innovation: the cluster approach. Paris: OECD Publications.

Owen-Smith, J. and Powell, W. W. 2004: Knowledge networks as channels and conduits: the effects of spillovers in the Boston biotechnology community. Organization Science 15, 221.

Parker, P. 2001: Local-global partnerships for high-tech development: integrating top-down and bottom-up models. Economic Development Quarterly 15, 149-167.

Pinch, S., Henry, N., Jenkins, M. and Tallmann, S. 2003: From 'industrial districts' to 'knowledge clusters': a model of knowledge dissemination and competitive advantage in industrial agglomerations. Journal of Economic Geography 3: 373-388.

Porter, M. E. 1990: The competitive advantage of nations. New York: Free Press.

Porter, M. E. 1998: Clusters and the new economics of competition. Harvard Business Review 76 (November-December), 77-90.

Porter, M. E. 2000: Locations, clusters, and company strategy. In Clark, G. L., Feldman, M. P. and Gertler, M. S., editors, The Oxford handbook of economic geography, Oxford: Oxford University Press, 253-274.

Porter, M. E. 2002: Einstellungen, Werte, Überzeugungen und die Mikroökonomie des Wohlstands (Attitudes, values, convictions and the microeconomics of welfare). In Harrison, L. E. and Huntington, S. P., editors, Streit um Werte. Wie Kulturen den Fortschritt prägen (Culture Matters), Hamburg: Europa Verlag, 37-55.

Porter, M. E. 2003: The economic performance of regions. Regional Studies 37, 549-578.

Power, D. 2002: 'Cultural industries' in Sweden: an assessment of their place in the Swedish economy. Economic Geography 78, 103-127.

Preissl, B. and Solimene, L. 2003: The dynamics of clusters and innovation. Heidelberg and New York: Physica. 
Rallet, A. and Torre, A. 2004: Proximity and localization. Paper presented at the 4th Congress on Proximity Economics 'Proximity, Networks and Co-ordination' in Marseille, 17-18 June.

Saxenian, A. L. 1994: Regional advantage: culture and competition in Silicon Valley and Route 128. Cambridge, MA, and London: Harvard University Press.

Sayer, A. 1997: The dialectic of culture and economy. In Lee, R. and Wills, J., editors, Geographies of economies, London and New York: Arnold, 16-26.

Schoenberger, E. 1999: The firm in the region and the region in the firm. In Barnes, T. J. and Gertler, M. S., editors, The new industrial geography: regions, regulation and institutions, London: Routledge, 205-224.

Scott, A. J. 1998: Regions and the world economy: the coming shape of global production, competition, and political order. Oxford and New York: Oxford University Press.

Simmie, J. 2003: Innovation and urban regions as national and international nodes for the transfer and sharing of knowledge. Regional Studies 37, 607-620.

Smith, A. 2003: Power relations, industrial clusters, and regional transformations: panEuropean integration and outward processing in the Slovak clothing industry. Economic Geography 79, 17-40.

Sofer, M. and Schnell, I. 2002: Over- and under-embeddedness: failures in developing mixed embeddedness among Israeli Arab entrepreneurs. In Taylor, M. and Leonard, S., editors, Embedded enterprise and social capital: international perspectives, Aldershot: Ashgate, 207-224.

Sternberg, R. and Litzenberger, T. 2003: Regional clusters - operationalisation and consequences for entrepreneurship. University of Cologne. Department of Economic and Social Geography Working Paper 2003-02.

Storper, M. 1997: The regional world: territorial development in a global economy. New York and London: Guilford.

Storper, M. and Venables, A. J. 2004: Buzz: face-to-face contact and the urban economy. Journal of Economic Geography 4, 351-370.

Taylor, M. 2000: Enterprise, power and embeddedness: an empirical exploration. In Vatne, E. and Taylor, M., editors, The networked firm in a global world: small firms in new environments, Aldershot, Burlington: Ashgate, 199-233.

Taylor, M. 2005: Embedded local growth: a theory taken too far? In Boschma, R. A. and Kloosterman, R., editors, Clustering, learning and regional development: a critical assessment, Dordrecht: Springer, forthcoming. 
Thrift, N. J. 1996: Spatial formations. London: Sage.

Thrift, N. 2000: Performing cultures in the new economy. Annals of the Association of American Geographers 90: 674-692.

Tracey, P. and Clark, G. L. 2003: Alliances, networks and competitive strategy: rethinking clusters of innovation. Growth and Change 34, 1-16.

Uzzi, B. 1997: Social structure and competition in interfirm networks: the paradox of embeddedness. Administrative Science Quarterly 42, 35-67.

Vatne, E. 2001: Local versus extra-local relations: the importance of ties to information and the institutional and territorial structure of technological systems. Paper presented at the joint conference of the International Geographical Union (IGU) Commission on the Dynamics of Economic Spaces and the IGU Study Group on 'Local Development: Issues of Competition, Collaboration and Territoriality' in Turin, 9-14 July.

Wenger, E. 1998: Communities of practice: learning, meaning, and identity. Cambridge: Cambridge University Press.

Wenger, E. C. and Snyder, W. M. 2000: Communities of practice: the organizational frontier. Harvard Business Review 78 (January-February), 139-145.

Wolfe, D. A. and Gertler, M. S. 2004: Clusters from the inside and out: local dynamics and global linkages. Urban Studies 41, 1071-1093.

Yeung, H. W.-c. 1994. Critical reviews of geographical perspectives on business organizations and the organization of production: towards a network approach. Progress in Human Geography 18, 460-490. 
